\title{
MAPEAMENTO GEOMORFOLÓGICO DA BACIA DO IGARAPÉ BELMONT PORTO VELHO - RONDÔNIA
}

\section{GEMORPHOLOGICAL MAPPING BELMONT STREAM BASIN PORTO VELHO - RODÔNIA}

\begin{abstract}
Salem Leandro Moura dos Santos
Universidade Federal de Rondônia - UNIR. R: Vitor de Abreu, 7685 Bairro JK 1 - Porto Velho - RO. CEP: 76.829-408.

e-mail: salemsantos@yahoo.com.br
\end{abstract}

Eloiza Elena Della Justina

Departamento de Geografia da Universidade Federal de Rondonia - UNIR. - Campus José Ribeiro Filho, BR-364, km 9,5, sentido Acre. Porto Velho-RO, CEP78.900-970.e-mail: eloisaelena.della@hotmail.com

Maria Madalena Ferreira

Departamento de Geografia da Universidade Federal de Rondônia-UNIR. - Campus José Ribeiro Filho, BR-364, km 9,5, sentido Acre.Porto Velho-RO, CEP 78.900-970.e-mail: madhafer2004@yahoo.com.br

\section{Informações sobre o Artigo}

Data de Recebimento:

25/07/2011

Data de Aprovação:

$01 / 10 / 2012$

\section{Palavras-chave:}

Morfometria, Táxons,

Vertentes.

\section{Keywords:}

Morphmetry, Taxons, Slopes.

\begin{abstract}
Resumo
Este estudo apresenta a classificação geomorfológica da bacia do Igarapé Belmont na cidade de Porto Velho - RO, em uma escala de detalhe de 1:25.000, onde os diferentes padrões de organização do relevo foram mapeados. Para este estudo, foi utilizada a metodologia Taxonômica de Representação Cartográfica do Relevo do IBGE (BRASIL, 1995), (ROSS, 1992), o qual se parte de um $1^{\circ}$ táxon de escala pequena, que representa as grandes estruturas geológicas regionais da área, para outros 5 táxons menores afim de representar as unidades do relevo, para isso, foram utilizados dados de Sensoriamento Remoto (imagens aérea e de radar), dados do Plano Agropecuário e Florestal de Rondônia - PLANAFLORO, dados geológicos da CPRM (BRASIL, 1990) e coletas de dados em campo, que foi possível classificar as unidades morfológicas da bacia do Igarapé Belmont. Como resultado foram mapeados na área 2 tipos de Gênesis: Agradacional, contendo 2 tipos de relevos: Terraços Fluviais (Atf) e as Planícies Fluviolacustre (Apfl); e o Modelado Denudacional, contendo 8 tipos de relevos: Denudacional Estrutural Tabular (DEt 14, DEt 13, DEt 12, DEt 23, DEt 24), Denudacional Tabular (Dt 14, Dt 13, Dt 12). Em cada modelado foram também classificadas as formas das vertentes .
\end{abstract}

\begin{abstract}
This study show the classification of geomorphological Belmont Stream Basin in the city of Porto Velho - RO, in a detailed scale of 1:25,000, where different patterns of organization of relief were mapped. For this study, the methodology Taxonomic Representation Cartographic Relief of the IBGE (BRASIL, 1995), (ROSS, 1992), which is part of a taxon
\end{abstract}


$1^{\mathrm{o}}$ small scale, which represents the major geological structures of the regional area, 5 for other taxons in order to represent smaller units of relief, for this, it was used remote sensing data (aerial photos and radar), data of the Plan of Agricultural and Forest of Rondônia - PLANAFLORO, geological data of the CPRM (BRASIL,1990) and data collection in the field, it was possible to classify the morphological units of the Belmont Stream basin. As a result were mapped in the two types of Genesis: Agradacional containing two types of relief: Terraces (Atf) and the Plains Fluviolacustre (Apfl) and Modeled Denudacional containing eight types of relief: Structural Denudacional Tabular (DEt14, DEt13, DEt12, DEt23, DEt24), Denudacional Tabular (Dt14, Dt13, Dt12). In each modeled were also classified forms of the slopes.

\section{Introdução}

O mapeamento geomorfológico é o resultado da aplicação de metodologias para a compreensão da forma e da dinâmica da paisagem, pois uma vez espacializa os fenômenos, fornecendo uma compreensão multidisciplinar do relevo em análise.

Conforme Ross (1992), o produto síntese do mapeamento é basicamente qualitativo, mas que permite um diagnóstico síntese dos aspectos geomorfológicos da área e pode nortear as intervenções antrópicas futuras e corrigir as presentes, se constituindo em um importante instrumento para o planejamento físico territorial.

Argento (1998, p. 366) afirma que os mapeamentos geomorfológicos priorizam a ordenação dos fenômenos mapeados, a qual deve estar de acordo com uma determinada escala geográfica. Para isto, o mapeamento deve expressar as formas fisiográficas e considerar as interações de elementos como solos, clima, vegetação, antropismo, conforme a escala de trabalho da paisagem.

Os estudos de Tricart (1965) destacam como o relevo terrestre pode ser classificado. Tornando-se umas das primeiras metodologias a serem utilizadas no Brasil:

$\checkmark$ Relação de tempo e espaço; quanto maior for à extensão da unidade morfológica mais idade ela terá.

$\checkmark$ Dimensão e tamanho; as formas morfológicas são expressas em quilômetros quadrados, visando à qualificação do tamanho de cada feição.

$\checkmark$ Relação clima e relevo; analisa as relações do clima na influência das formas do relevo.

$\checkmark$ Relação tempo com a taxonomia; relaciona o tempo da formação de cada táxon, com a escala de tempo geológica de cada unidade do relevo, determinando o tempo de formação de cada táxon.

Neste pensamento metodológico, Rodrigues (1998) informa que metodologicamente todos os mapas geomorfológicos apresentam 4 características básicas para interpretar o relevo em qualquer escala:

\footnotetext{
$\checkmark$ Morfometria (cálculos da altimetria, dimensões, declives)

$\checkmark$ Morfologia (classificação de tipos de vertente, topos, fundo de vales, rupturas)

$\checkmark$ Gênesis (relevos do tipo agradacional ou denudacional)

$\checkmark$ Cronologia (Idades relativas das formações)
}

O mapeamento geomorfológico tem por princípio a ordenação hierárquica dos fatos geomorfológicos, a fim de que possam representá-los em uma metodologia que agrupe os sucessivos conjuntos de modelados de relevo em unidades geomorfológicas (ROSS, 1992). Esta forma de mapeamento exige a criação de ordens de análise de grandezas, que possam explicar em cada ordem a forma do relevo, evolução e tendências futuras. (BRASIL, 1995, p. 11).

Este estudo tem por objetivo mapear e classificar as feições geomorfológicas da bacia do Igarapé Belmont na cidade de Porto Velho - RO, fundamentada nos conceitos de análise morfológica da paisagem, tendo como base a metodologia de classificação taxonômica cartográfica do relevo conforme o Instituto Brasileiro de Geografia e Estatísticas - IBGE (BRASIL, 1995) e Jurandyr Luciano Sanches Ross (1992).

A bacia do Igarapé Belmont, localizada no município de Porto Velho - Rondônia, é classificada como área semi-rural em franca expansão para jusante do Igarapé. Nesta área, os mapas cartográficos geomorfológicos estão em pequenas e médias escalas de análise. O mapa geomorfológico de maior detalhe, que está em uma escala de 1:250.000, foi elaborado pelo Plano Agropecuário e Florestal de Rondônia - PLANAFLORO (RONDÔNIA, 2002).

A ausência de um mapeamento geomorfológico de escala de detalhe na bacia do Belmont é notada na localização de atividades urbanas e rurais em locais não apropriados, como em áreas de nascentes do Igarapé, várzeas e vertentes, que em sua maioria encontram-se em um estado de degradação ambiental.

A bacia apresenta uma extensão de $126,5 \mathrm{~km}^{2}$ e está localizada nas coordenadas $08^{\circ} 39^{\prime} 02^{\prime \prime} \mathrm{S}$ e $08^{\circ} 46^{\prime} 12^{\prime \prime} \mathrm{S}$; $63^{\circ} 48^{\prime} 41^{\prime \prime} \mathrm{O}$ e $63^{\circ} 54^{\prime} 48^{\prime \prime}$ O. A cidade de Porto Velho -RO localiza-se ao sul da bacia, onde se encontra a maior parte das nascentes do Igarapé. O médio e baixo curso do Igarapé encontra-se em zona rural, que abriga formas de atividades agrícolas e pastoris. Deve-se destacar, no médio curso do Igarapé localiza-se a área do Parque Municipal Natural Olavo Pires, que já sofre os efeitos da degradação ambiental de seu entorno. O Parque é popularmente conhecido como Parque Ecológico, sua área e a sua zona de amortecimento constituem uma área verde de mais de 2.000 hectares, tendo como seu principal afluente o Igarapé Belmont (PORTO VELHO, 2003). 
A foz do Igarapé localiza-se à noroeste da bacia do Belmont, situada à margem direita do médio curso do Rio
Madeira, onde também localiza-se o Lago do Belmont (Figura 1).

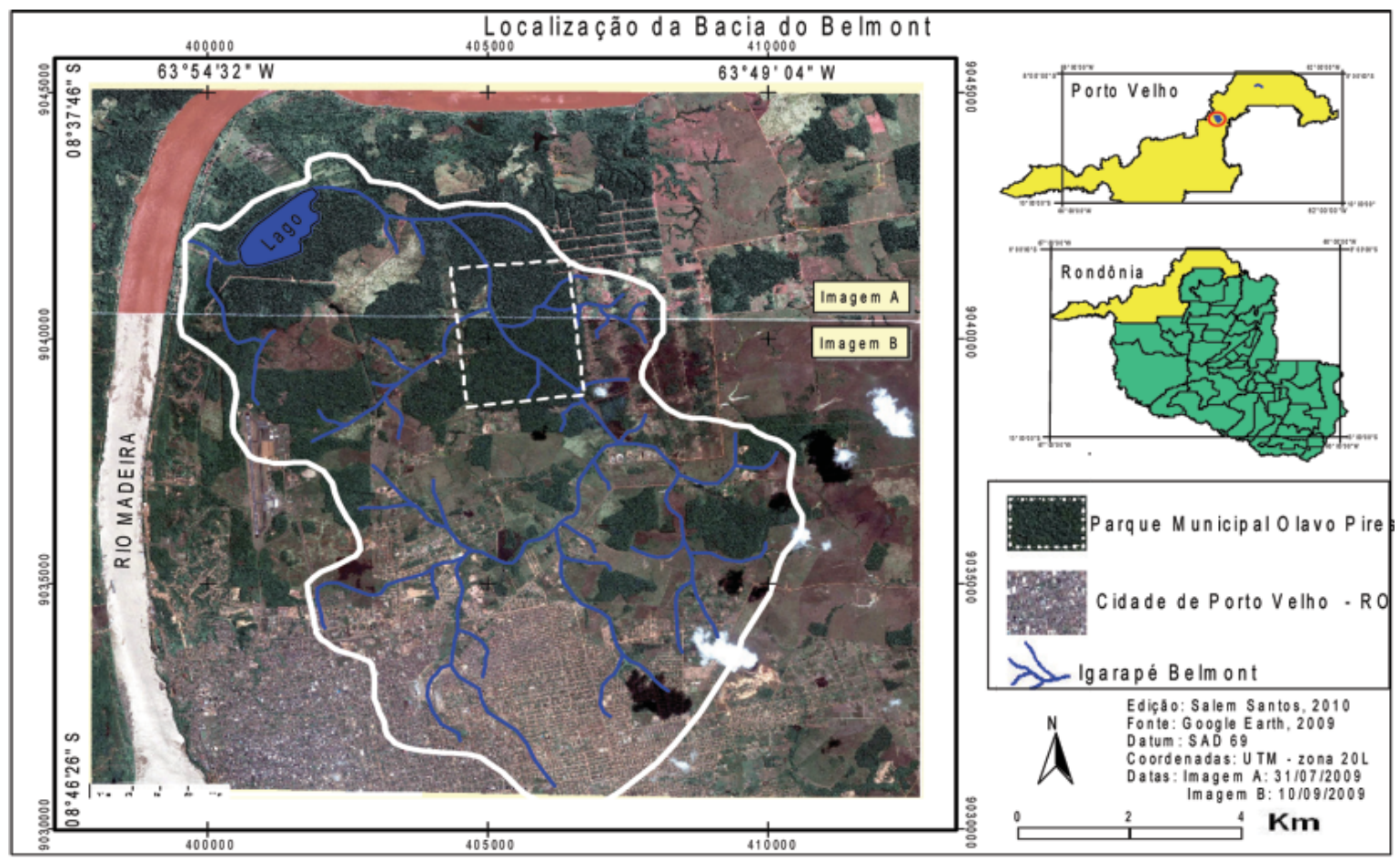

Figura 1 - Chave de Interpretação da Bacia do Belmont (SANTOS, 2010).

\section{Geologia da bacia}

A Geologia, para os estudos geomorfológicos apresenta-se como um estudo indispensável para a caracterização dos materiais em que as formas do relevo estão dispostas, pois, antes da pesquisa geomorfológica é necessário ter dados geológicos da área, para uma interpretação correta da morfogênese do relevo. Ferreira (2005, p. 39), informa que a análise dos tipos de rochas, falhas, decomposições e movimentos discriminam o tempo geológico da área como também explica em parte as formas atuais do relevo.

A área da Bacia do Igarapé Belmont apresenta os embasamentos: Complexo Jamari (APjl), constituído por rochas metamórficas como granitóides folheados, gnaisses, migmatítos, anfibolitos, granulitos que encontram-se em todo o estado de Rondônia. (BRASIL, 1990, p. 65). Logo acima do embasamento cristalino do Complexo Jamari na Bacia do Igarapé Belmont, encontra-se o Domínio das Coberturas Cenozóicas (Figura 2).

As coberturas ocorrem com maior expressividade na Subprovíncia Madeira, representada pelos sedimentos fluviais, colúvio-aluviais e lateritos maturos e imaturos e está relacionada com a evolução do relevo da região, através dos fatores climáticos e estruturais, que ocasionaram o aparecimento de relevos estruturais, erosivos e de acumulação (BRASIL, 1990, p. 19).

Verifica-se no mapeamento realizado por Brasil (1990, 2007), que a Bacia do Belmont apresenta sedimentos aluviais, depósitos fluviais e colúvio-aluviais pretéritos, em áreas próximas da foz e do lago do Igarapé. Essas coberturas do Pleistoceno-Holoceno denominadas de Coberturas Sedimentares Indiferenciadas (NQi), são associações sedimentares extremamente heterogêneas, remanescentes das fases iniciais do ciclo de pediplanação, formando rampas de colúvio-aluviais, que expressam episódios climáticos que favoreceram o escoamento superficial difuso (BRASIL, 1990, 2007).

De acordo com Brasil (1990, 2007), próximo à várzea do Rio Madeira e do lago do Belmont a bacia do Belmont apresenta sedimentos recentes, provindo da alta do nível d'água do Rio Madeira.

Esses sedimentos aluviais recentes são derivados das drenagens atuais, que são identificados como Depósitos Aluvionares $(\mathrm{Q} 2 \mathrm{a})$. Essa cobertura é periodicamente inundável nas cheias dos rios, estão relacionadas com o posicionamento atual das drenagens que se instalaram no Holoceno em condições de climas atuais (BRASIL, 1990, 2007). 
Nas análises de Brasil (1990), concluiu-se que à espessura máxima das Coberturas de superfícies Sedimentares Indiferenciadas sob o embasamento cristalino não ultrapassa a média de 40 metros. Nesta seção sedimentar, há presença de cortes fluviais e areias espalhadas pela área, constatando-se que são depósitos colúvio-aluviais. São sedimentos geneticamente associados a processos erosivos e deposicionais relacionados com a alternância dos períodos de clima tropical úmido e seco desde o Pleistocênico inferior até o Holoceno.

As Coberturas Detrito-Lateríticas (NQdi) representam todos os afloramentos lateríticos na Bacia do Belmont, equivalem aos plintitos e petroplintitos. Os lateritos são encontrados no interior de perfis e barrancos de rios e igarapés, que estão relacionados com o próprio afloramento ou oscilação do lençol freático durante o Holoceno (BRASIL, 1990) (Figura 2).

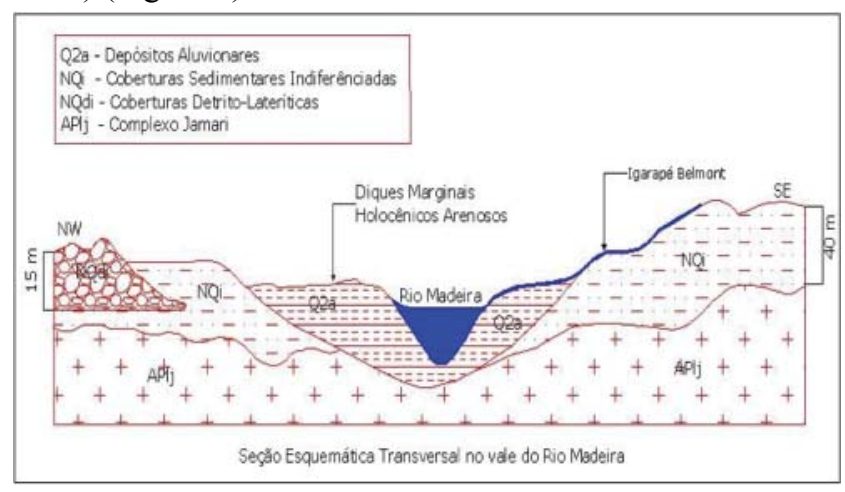

Figura 2 - Corte esquemático longitudinal da bacia do Igarapé Belmont e transversal do Rio Madeira. (Fonte: BRASIL, 1990). Adaptação: SANTOS, 2010.

A bacia do Igarapé Belmont abriga duas falhas geológicas confirmadas por Brasil (1990, p. 87), uma de noroeste à sudeste, que pertence ao lineamento Araras de sistema de falhas. A outra falha é de nordeste à sudoeste, que pertence ao lineamento Madeira-Quartoze de Abril. O lineamento Araras estabelece contato tectônico entre as coberturas sedimentares da Formação do Complexo Jamari.

O sistema de fraturas NW-SE é considerado como o mais antigo por se apresentar seccionado pelo sistema NE-SW, apesar de que a falha NW-SE sofreu processos de reativações após o seccionamento pela falha mais nova, que atingiram as rochas arqueanas e proterozóicas do Complexo Jamari apresentando uma inversão de idades entre as falhas (BRASIL, 1990).

\section{Geomorfologia da bacia}

Segundo Brasil (1990) a área do Igarapé Belmont está localizada no Planalto Brasileiro e morfologicamente no Planalto Rebaixado da Amazônica Ocidental, e que mais tarde foi classificado de Planalto Rebaixado de Rondônia.
Esta região é caracterizada por um relevo arrasado de morrotes residuais de topos aplainados ou mamelonares, trechos de dissecação suave, gerando interflúvios com resíduos das épocas do terciário e quaternário (BRASIL, 1990, p. 49).

A região onde a bacia do Igarapé Belmont se localiza, conforme Brasil $(1990,2007)$, pertence ao domínio morfoestrutural das Coberturas Sedimentares Fanerozóicas, localizada na unidade geomorfológica da Depressão de Porto Velho, em que foi esculpido um relevo homogêneo, com poucos desníveis altimétricos, constituindo uma área deprimida, que predominam interflúvios tabulares originados em coberturas sedimentares, rochas metamórficas e lateritas que apresenta eventual controle estrutural, que foram definidos como redes de drenagem de fraca densidade, com vales rasos, que apresenta vertentes de pequenas declividades, que são caracterizados por vales bem-definidos em formas retilíneas e vertentes com declividades variadas, entalhadas por sulcos e cabeceiras de drenagem de primeira e segunda ordem em formato geralmente retangular.

Esta área apresenta depósitos pleistoceno-holocênicos com contatos com materiais areno-argilosos, produzidos pelo retrabalhamento físico-químico dos lateritos que desenvolveram-se sobre o Complexo Jamari. Essas concreções lateríticas por serem mais resistentes a erosão do que os depósitos sedimentares, apresentam colinas lateríticas, que podem ser recobertas por materiais areno-argilosos ou aflorantes, que modifica a forma dos interflúvios e o aprofundamento das drenagens na Depressão Porto Velho.

Brasil (1982) classificou essa área, em uma escala pequena que generalizou a Depressão Porto Velho, como Denudacional Tabular de média dimensão interfluvial e de entalhamento dos vales - Dt 33. Visto que, em uma escala detalhada esse tipo de relevo apresenta maior densidade de drenagem e declividade.

Os pediplanos e os pedimentos na área teriam sido gerados por condições de climas secos. Que foram destruídos e remodelados pela superposição dos ciclos úmidos subsequentes. A definição dos cursos dos rios e igarapés atuais deve ter ocorrido no limite do Pleistoceno - Holoceno, quando o clima tornou-se mais úmido. Durante o final do Pleistoceno ainda predominava o clima seco com chuvas torrenciais sazonais, no qual foi elaborado um vasto aplainamento de âmbito continental que resultou na superfície de erosão denominada Pediplano Neopleistocênico (BRASIL, 1990).

Brasil (1982) verificou que, próximo as margens do rio Madeira, o relevo da Depressão Porto Velho torna-se plano com acumulação sedimentar aluvial e coluvial, sendo classificado como Terraços Fluviais (Atf) (Figura 3).

Este tipo de relevo, apresenta-se no baixo curso do Igarapé Belmont, com diversas áreas alagadiças e a presença de um lago perene. 


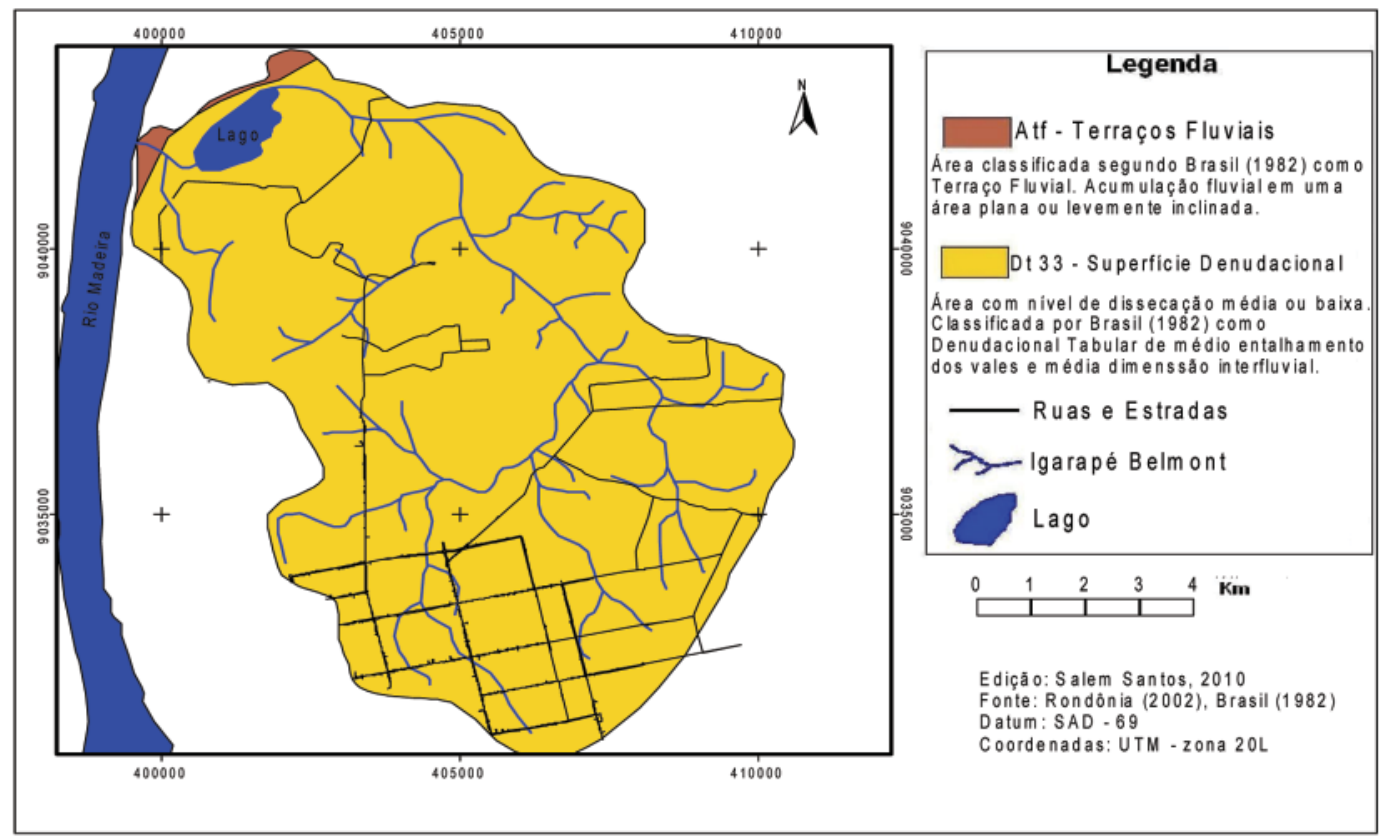

Figura 3 - Geomorfologia da Bacia do Belmont, segundo dados do PLANAFLORO (RONDÔNIA, 2002). Edição: SANTOS, 2010.

Segundo Brasil (1990), estes terraços fluviais formaram-se na época do Mioceno, Plioceno e Pleistoceno. Durante estas épocas, essas áreas sofreram a última movimentação de falhas que atingiram as rochas Cambrianas, Mesozóica e Cenozóicas da região. Ocorreram soerguimentos de extensas áreas e subsidências de várias regiões, como do baixo curso do Rio Madeira, forçando mudanças na rede de drenagem para áreas mais baixas onde estão as falhas atuais ativas, transformando os diques marginais e leitos fluviais, abandonados, em terraços fluviais.

Os estudos de Santos (2008) apontam que as vertentes da área possuem uma área de drenagem com ângulo médio de inclinação de $2^{\circ}$ com a horizontal, caracterizando a Bacia como uma área semi-plana com poucos morros mamelonizados e isolados, com altitude inferior a 110 metros. Na confluência do Igarapé com o Rio Madeira a área sofre influência da dinâmica fluvial do Rio Madeira. As declividades em geral são iguais ou menores que $1^{\circ}$, apresentando baixas dissecações e, a altitude média da bacia fica próxima aos 75 metros.

\section{Metodologia}

A metodologia empregada para este mapeamento geomorfológico foi a de taxonômia do relevo, confome IBGE (BRASIL, 1995).

Ross (1992) apresenta a proposta taxonômica de representação cartográfica do relevo, desde escalas pequenas até escalas de detalhe, sem que se perdesse a fidelidade das representações. Que apresenta seis tipos de táxons para classificar o relevo (Figura 4).
Para esta metodologia os táxons são proporcionais à escala de estudo, pois cada táxon tem um limite mínimo e máximo de escala para representar o relevo (GUERRA \& MARÇAL, 2006, p. 117).

$1^{\circ}$ Táxon - Unidades Morfoestruturais - É o maior táxon corresponde às macroestruturas geológicas que definem e sustentam um determinado padrão de formas grandes do relevo, cuja escala varia de 1:1.000.000 à 1:500.000.

$2^{\circ}$ Táxon - Unidades Morfoesculturais - Correspondem aos compartimentos e subcompartimentos do relevo pertencente a uma determinada morfoestrutura posicionados em diferentes níveis topográficos, gerados a partir de alterações climáticas. Obrigatoriamente são menores e mais jovens que as unidades morfoestruturais as quais pertencem, cuja escala varia de 1:500.000 à 1:100.000.

$3^{\circ}$ Táxon - Unidades Morfológicas - São conjuntos menores de formas do relevo. Apresentam um padrão de semelhança entre si em função da rugosidade topográfica, bem como do formato de topos, vertentes e vales de cada padrão. Neste táxon os processos morfoclimáticos atuais são mais facilmente notados podendo-se identificar os agrupamentos de formas de agradação (relevo de acumulação) e formas de denudação (relevo de dissecação), cuja escala varia de $1: 100.000$ à 1:50.000.

$4^{\circ}$ Táxon - Tipos de Formas de Relevo - Corresponde às tipologias de modelado. Formas aguçadas, convexas, tabulares, aplainadas em relevos de agradação e de denudação, planícies fluviais e flúvio-lacustres, cuja escala varia de $1: 50.000$ à $1: 25.000$, 
$5^{\circ}$ Táxon - Tipos de Vertentes - São vertentes ou setores das vertentes, dimensões menores do relevo, quer sejam do tipo convexos, retilíneos, aguçados, planos, abruptos, cuja escala varia de 1:25.000 à 1:10.000.

$6^{\circ}$ Táxon - Formas Menores de Relevo ou de Processos Atuais - $\mathrm{O}$ menor táxon. São formas geradas por processos erosivos e acumulativos atuais como as voçorocas, ravinas, deslizamentos, assoreamentos, depósitos aluvionares de inundação, bem como cortes, aterros, desmontes de morros e outras formas produzidas pelo homem. Só podem ser representados em trabalhos com escalas grandes (ROSS, 1992, p. 21), cuja escala varia de 1:10.000 ou maior.

Os estudos de ações naturais ou antrópicas, em vertentes ou formas de processos atuais, devem ser representados a partir de 1: 25.000, 1: 10.000 ou 1: 5.000 , para evitar generalizações espaciais (ROSS, 1992) (Figura 4).

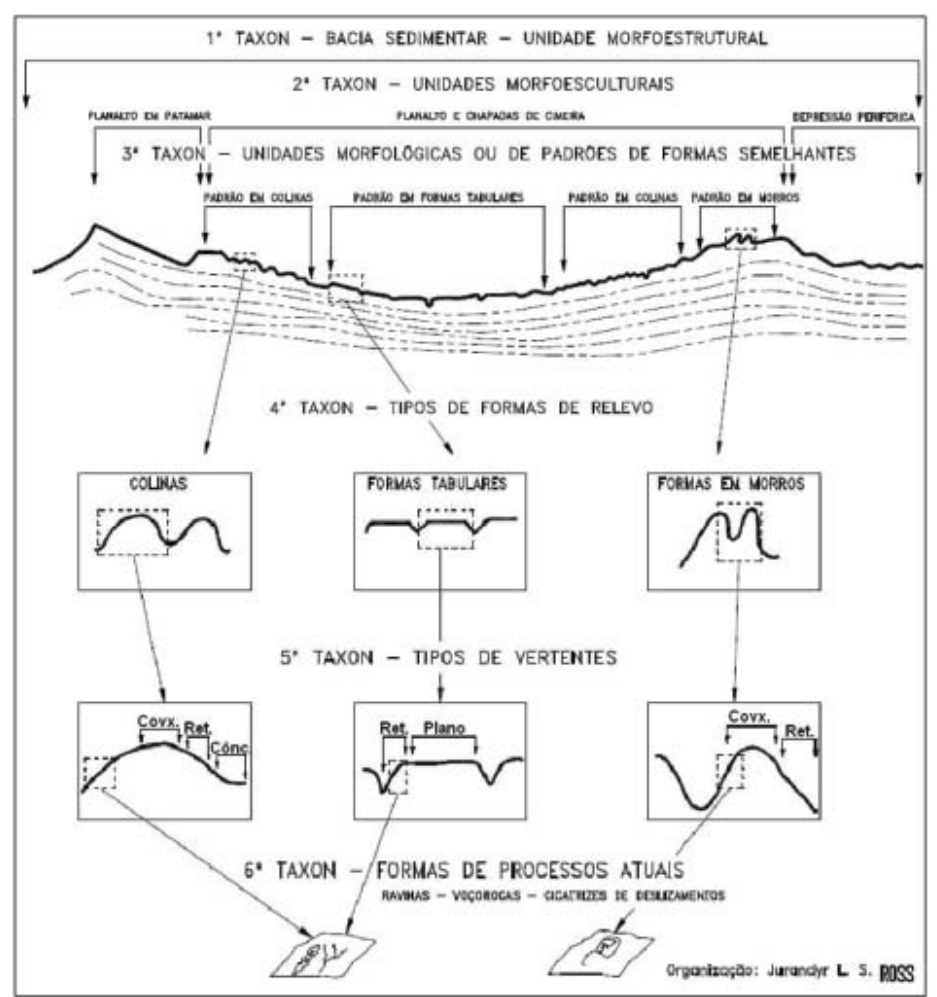

Figura 4 - Classificação Taxonômica do Relevo (ROSS, 1992, p. 24).

O $5^{\circ}$ foi representado apenas por símbolos, no mapeamento, pois na escala em questão não é aconselhável a criação de polígonos para representar as formas desses táxons devido ao seu tamanho reduzido na escala do mapa. Para este estudo, optou-se por uma escala de detalhe de 1:25.000.

Este estudo teve como base a carta planimétrica e o mapa temático de geologia da CPRM, Porto Velho (SC.20V-B-V) 1:100.000 e 1:1.000.000 (BRASIL, 1990, 2007); carta topográfica da DSG, Porto Velho, (SC.20-V-B-V-1), 1:50.000 (BRASIL, 1972); Mapa de geomorfologia do Banco de Dados Digital do PLANAFLORO, 1:250.000 (RONDÔNIA, 2002).

Para auxiliar a construção do mapa geomorfológico da bacia do Belmont, foi também utilizada a imagem do Shuttle Radar Topography Mission (SRTM) com resolução de 90m, corrigida com auxílio da base planimétrica digital no programa AutoCAD da Secretaria Municipal de Planejamento de Porto Velho (SEMPLA), na escala de 1:10.000, com curvas de nível em 1 metro. A imagem SRMT foi utilizada como modelo digital do terreno representando as feições do relevo para a confecção do mapa de contorno da bacia, como também foi utilizada para a visualização, georreferenciamento das formas do relevo com medições interfluviais e de elevação, que auxiliaram na construção do mapa de geomorfologia, com inserção de polígonos, pontos, linhas e atributos.

A extração de informações nos mapas e imagens, tiveram a seguinte ordem:

$\checkmark$ Identificação da drenagem e limitação física da bacia do Igarapé Belmont.

$\checkmark$ Identificação dos grandes compartimentos Morfoestruturais de acordo com a escala de trabalho.

$\checkmark$ Identificação das unidades Morfoesculturais de acordo com o mapa Geomorfológico do PLANAFLORO (RONDÔNIA, 2002).

$\checkmark$ Identificação das classes e feições do relevo como formas planas, dissecadas, aguçadas.

$\checkmark$ Identificação de erosões, modificações antrópicas, utilizando imagens do programa Google Earth.

$\checkmark$ Interpretação de campo da paisagem natural, a fim de interpretar o estágio atual do relevo.

Para a dissecação do relevo foi utilizada a matriz de dissecação de relevo proposto por Brasil (1982), em que classifica os vales em entalhamento (de muito fraco a muito forte), e dimensão interfluvial (largura) do vale que pode variar de muito pequeno $(<250 \mathrm{~m})$ a muito grande $(>3.750$ m) (Figura 5).

\begin{tabular}{|c|c|c|c|c|c|}
\hline \multirow{2}{*}{$\begin{array}{c}\text { Graus de Entallhamento } \\
\text { dos Vales (classes) }\end{array}$} & \multicolumn{5}{|c|}{ Dimensăo Interfluvial Média (classes) } \\
\hline & $\begin{array}{c}\text { Muito Grande } \\
\left(\begin{array}{c}3.750 \mathrm{~m}) \\
\underline{1}\end{array}\right.\end{array}$ & $\begin{array}{c}\text { Grande } \\
(1750 \mathrm{a} 3.750 \mathrm{~m}) \\
\underline{\mathbf{2}}\end{array}$ & $\begin{array}{c}\text { Média } \\
(750 \mathrm{a} 1750 \mathrm{~m}) \\
\underline{\mathbf{3}}\end{array}$ & \begin{tabular}{|c|} 
Pequena \\
$(250$ a $750 \mathrm{~m})$ \\
$\underline{4}$
\end{tabular} & $\begin{array}{c}\text { Muito Pequena } \\
(<250 \mathrm{~m}) \\
\underline{5}\end{array}$ \\
\hline $\begin{array}{c}\text { Muito Fraco }(<20 \mathrm{~m}) \\
1\end{array}$ & 11 & 12 & 13 & 14 & 15 \\
\hline $\begin{array}{c}\text { Fraco }(20 \mathrm{a} 40 \mathrm{~m}) \\
2\end{array}$ & 21 & 22 & 23 & 24 & 25 \\
\hline $\begin{array}{c}\text { Medio }(40 \text { a } 80 \mathrm{~m}) \\
\underline{3}\end{array}$ & 31 & 32 & 33 & 34 & 35 \\
\hline $\begin{array}{c}\text { Forte }(80 \text { a } 160 \mathrm{~m}) \\
4\end{array}$ & 41 & 42 & 43 & 44 & 45 \\
\hline $\begin{array}{c}\text { Muito Forte }(>160 \mathrm{~m}) \\
\underline{5}\end{array}$ & 51 & 52 & 53 & 54 & 55 \\
\hline
\end{tabular}

Figura 5 - Matrizes de dissecação do relevo 
Apesar que, Ross et. al. (2011) informa que o mapeamento em escala de detalhe deve ser utilizada a declividade do relevo como índice de dissecação e não a matriz de dissecação do relevo elaborada para o Projeto Radambrasil.

Para realizar o cálculo do entalhamento médio dos canais fluviais na área foi necessário obter a altimetria do local, calculada com o uso de um GPS (altitude relativa). Após a coleta dos dados de altitude do interflúvio e da lâmina d'água do ponto, subtraiu-se os valores para obter a altura da profundidade do vale. A largura dos interflúvios foi calculada com um GPS em campo, a partir das coordenadas do interflúvio e do curso d'água (distância dos dois pontos em um mapa de localização da área com coordenadas em UTM) (Figura 6).

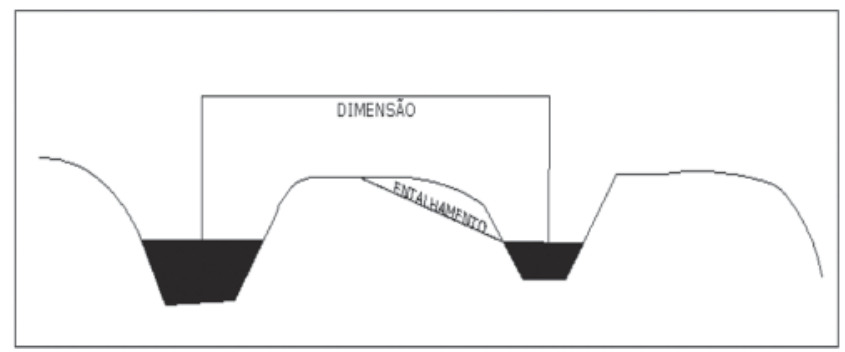

Figura 6 - Dissecação do Relevo proposto por Ross (1992). (Desenho: Santos, 2010).

Para o mapa geomorfológico da bacia do Belmont foram utilizados também como base as imagens do programa Google Earth de datas 31/07/2009 e 10/09/2009, sobreposta à imagem de radar do SRTM. Através da interpretação dessas imagens foram medidos o entalhamento e a distância interfluvial dos vales da Bacia, além da interpretação da tipologia da rede de drenagem do Igarapé, com que, foram produzido o mapa de contorno com os polígonos das unidades de relevo da Bacia no programa Global Mapper, que foram exportados em formato shapefile para o programa ArcView, para ser montado o mapa em um layout mais funcional, distinguindo suas unidades morfológicas e legendas de acordo com o tipo de relevo.

\section{Resultados}

A bacia do Igarapé Belmont foi classificada em 2 tipos de modelados de relevo, o Denudacional, com oito tipologias de formas de relevo e o Agradacional, com duas tipologias de formas de relevo:

Nas áreas Agradacionais, destacam-se:

1 - Terraços Fluviais (Atf) - Superfícies planas ou levemente inclinadas, constituídas por depósitos sedimentares dos períodos Terciário e Quaternário, que foram modelados topograficamente pela erosão fluvial do Rio Madeira e limitados por declives no mesmo sentido dos depósitos. Apresentam retomada dos processos erosivos de forma difusa com deposi- ção de sedimentos finos. Este relevo apresenta-se em patamares estruturais que interrompem o declive contínuo da área. Apresenta vertentes no formato convexo (Figuras 7 e 8).

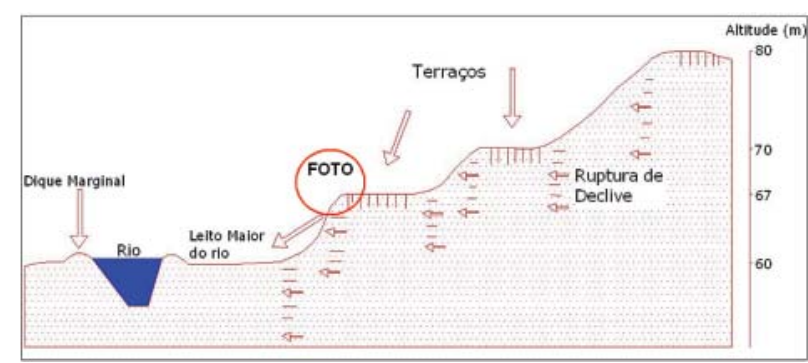

Figura 7 - Terraços Fluviais (Santos, 2010)

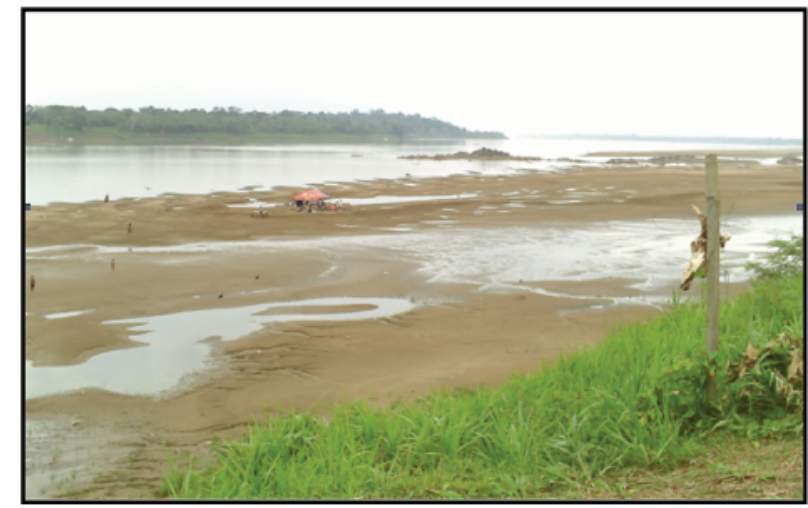

Figura 8 - Terraço e leito maior do Rio Madeira (Foto: Santos, 2010).

2 - Planície Fluviolacustre (Apfl) - Superfície deprimida, constituída por depósitos sedimentares recentes e subrecentes do período Quaternário. Neste relevo encontra-se o Lago do Belmont e as áreas de várzeas. Predominam a acumulação sedimentar fluvial intermitente e lagunar permanente. Os materiais depositados são finos, principalmente silte e argila, que se encontram em suspensão na água (Figura 9).

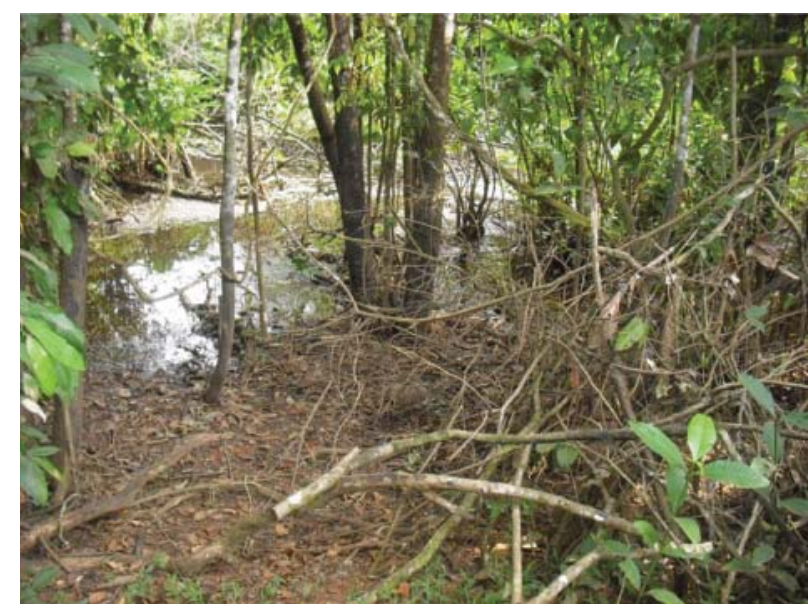

Figura 9 - Planície Fluviolacustre (Foto Santos, 2012). 
Nas áreas com modelados Denudacionais, destacam-se:

1 - Denudacional Estrutural Tabular com fraco entalhamento dos vales e pequena dimensão interfluvial (DEt 24) - Superfície dissecada, que apresenta fraco grau de entalhamento dos vales com 10 a 30 metros de profundidade, e pequena dimensão interfluvial que varia entre 400 a 730 metros de distância. Este modelado apresenta vertentes íngremes com formato côncavo. Sua superfície é eventualmente sustentada por coberturas Detrito-Lateríticas Imaturas em formas de colinas. A presença de falhas nestas áreas potencializa os processos de erosões lineares. (Figura 10).

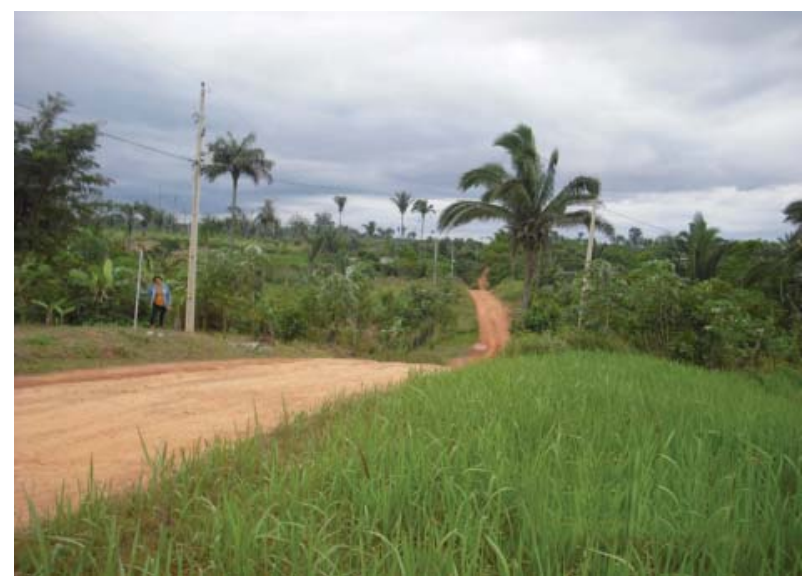

Figura 10 - Modelado DEt 24 (Foto: Santos, 2012).

2 - Denudacional Estrutural Tabular com fraco entalhamento dos vales e média dimensão interfluvial (DEt 23) Superfície dissecada, que se apresenta no formato de colinas, de fraco grau de entalhamento dos vales com 8 a 22 metros de profundidade, e média dimensão interfluvial variando entre 750 a 1.500 metros de distância. Esta superfície apresenta vertentes íngremes com formato côncavo, geralmente suas superfícies são sustentadas por coberturas Detrito-Lateríticas Imaturas. Esta unidade apresenta ser as colinas de concreções lateríticas da Bacia. (Figura 11).

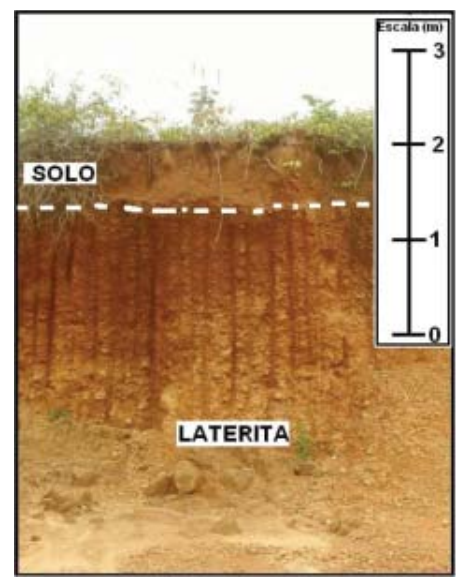

Figura 11 Concreção Lateritica na Bacia do Belmont (Foto: Santos, 2010).
3 - Denudacional Estrutural Tabular com muito fraco entalhamento dos vales e pequena dimensão interfluvial (DEt 14) - Superfície dissecada e deprimida da bacia do Belmont, com muito fraco grau de entalhamento dos vales com 2 a 7 metros de profundidade e pequena dimensão interfluvial que varia entre 400 a 750 metros de distância. Suas vertentes apresentam-se no formato convexo e escarpadas nas bordas e com linhas de falhas transcorrentes localizadas nesta área. A presença de falhas se manifesta no encaixamento dos canais e na forma da rede de drenagem. Esta superfície é constituída pelas áreas de fundo de vale do Igarapé (Figura 12).

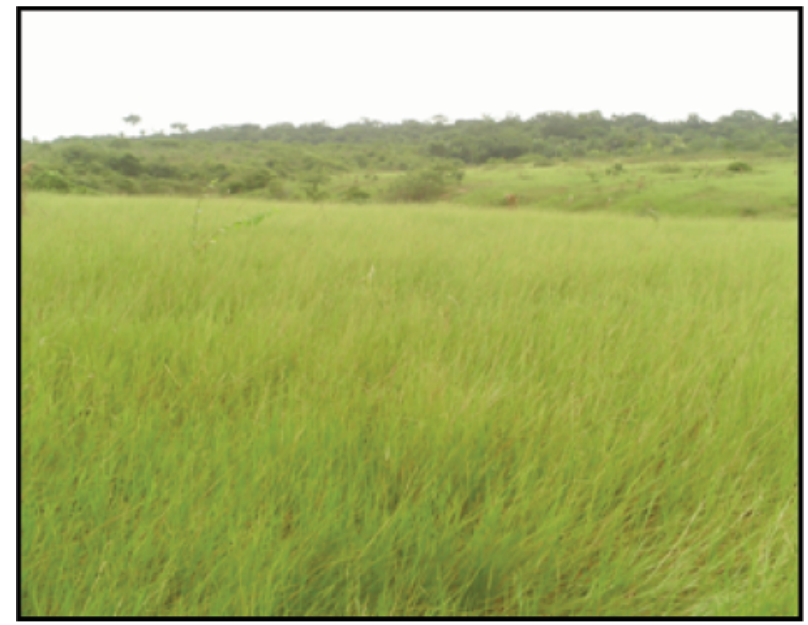

Figura 12 - Vale fechado (Foto Santos, 2012).

4 - Denudacional Estrutural Tabular com muito fraco entalhamento dos vales e média dimensão interfluvial (DEt 13) - Superfície dissecada e deprimida da bacia do Belmont, com muito fraco grau de entalhamento dos vales com 5 a 15 metros de profundidade e média dimensão interfluvial que varia entre 750 a 1.500 metros de distância. Suas vertentes apresentam formatos convexo e côncavo, com drenagem do Igarapé encaixada. Esta área está sujeita a inundações próximas ao curso d'água principal do Igarapé. A drenagem se encontra encaixada em linhas de falhas com registros regionais (Figura 13).

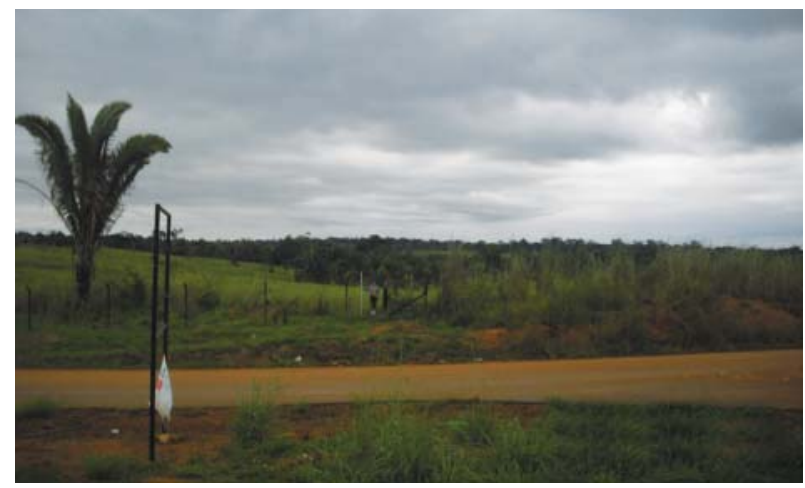

Figura 13 - Vale aberto (Foto: Santos, 2012); 
5 - Denudacional Estrutural Tabular com muito fraco entalhamento dos vales e grande dimensão interfluvial (DEt 12) - Superfície dissecada e plana, localizada entre linhas de falhas, que orientam os cursos d'águas do Igarapé, promovendo formato retangular da rede de drenagem. Apresenta muito fraco grau de entalhamento dos vales com 3 a 15 metros de profundidade e grande dimensão interfluvial que varia entre 3.000 a 3.700 metros de distância. As vertentes possuem formato côncavo, que concentra as nascentes do Igarapé (Figura 14).

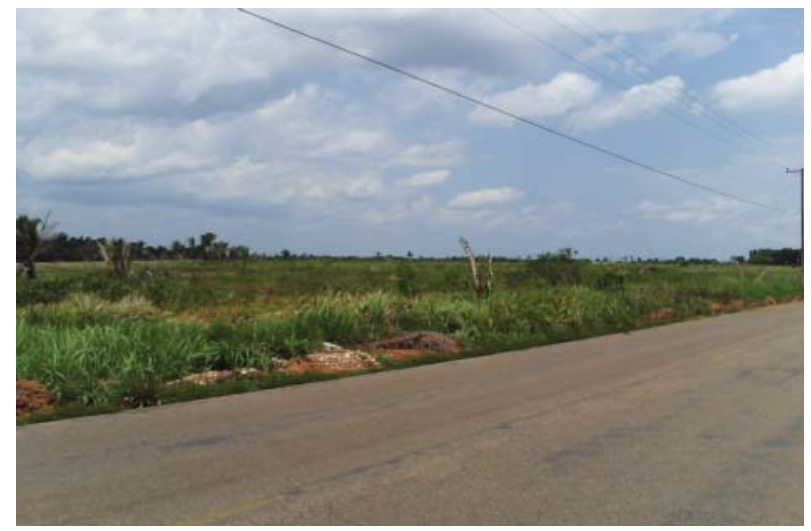

Figura 14 - Unidade de relevo DEt 12 (Foto: Santos, 2012).

6 - Denudacional Tabular com muito fraco entalhamento dos vales e pequena dimensão interfluvial (Dt 14) - Superfície dissecada e deprimida, localizada entre relevos denudacionais, com muito fraco grau de entalhamento dos vales com 9 a 18 metros de profundidade e pequena dimensão interfluvial variando entre 300 a 630 metros de distância, com vertentes no formato côncavo. Esta superfície constitui como área deprimida entre os modelados vizinhos. Que apresenta um formato embaciado, deprimido, sujeita a inundações e alagamentos (Figura 15).

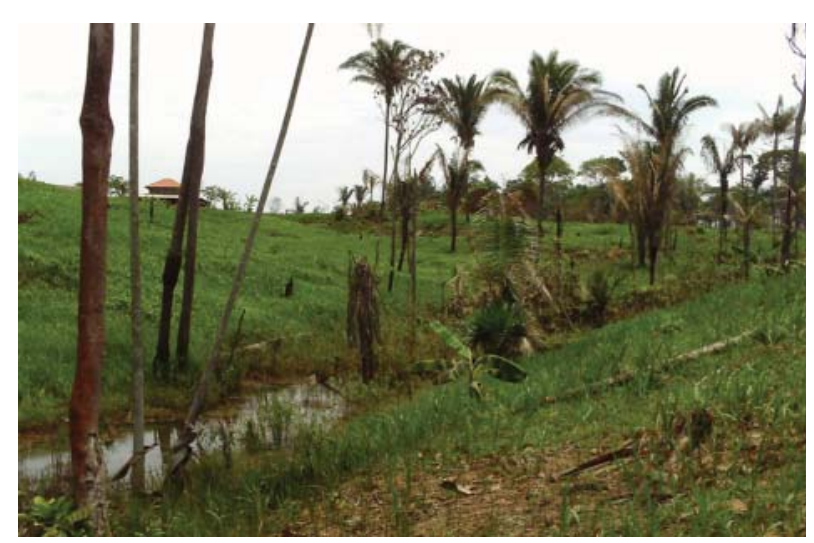

Figura 15 - Relevo embaciado com curso d'água (Foto Santos, 2012).
7 - Denudacional Tabular com muito fraco entalhamento dos vales e média dimensão interfluvial (Dt 13) - Superfície dissecada e plana, que abriga coberturas Detrito-Lateríticas em forma de colinas de topo plano, que se encontram mais elevados do que os relevos vizinhos, com muito fraco grau de entalhamento dos vales entre 3 a 10 metros de profundidade e média dimensão interfluvial variando entre 750 a 1.300 metros de distância. Suas vertentes apresentam formato côncavo (Figura 16).

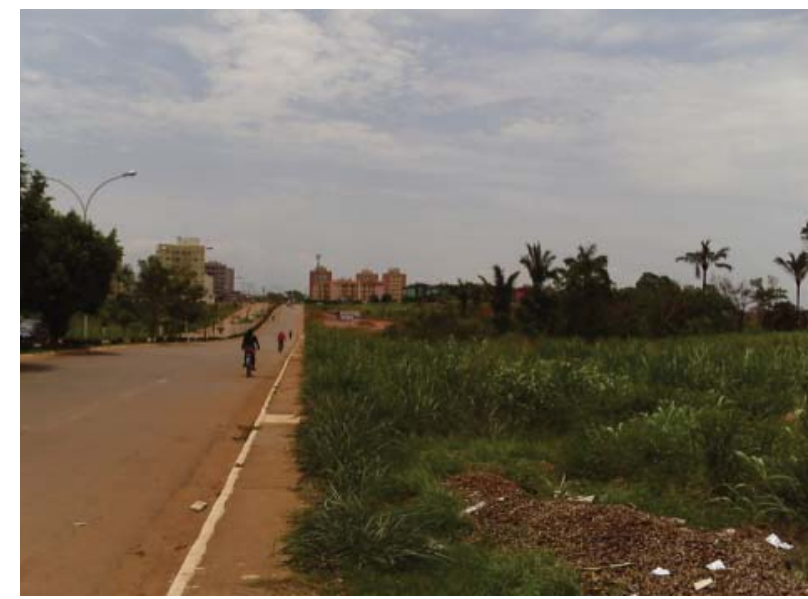

Figura 16 - Unidade de relevo Dt 13 (Foto: Santos, 2012).

8 - Denudacional Tabular com muito fraco grau de entalhamento dos vales e grande dimensão interfluvial (Dt 12) - Superfície dissecada e plana que apresenta características de embaciamento, por ser uma área mais deprimida em relação aos modelados vizinhos, com muito fraco grau de entalhamento dos vales com 2 a 6 metros de profundidade e grande dimensão interfluvial que varia entre 1.800 a 2.700 metros de distância. As vertentes deste modelado apresentam o formato côncavo (Figura 17).

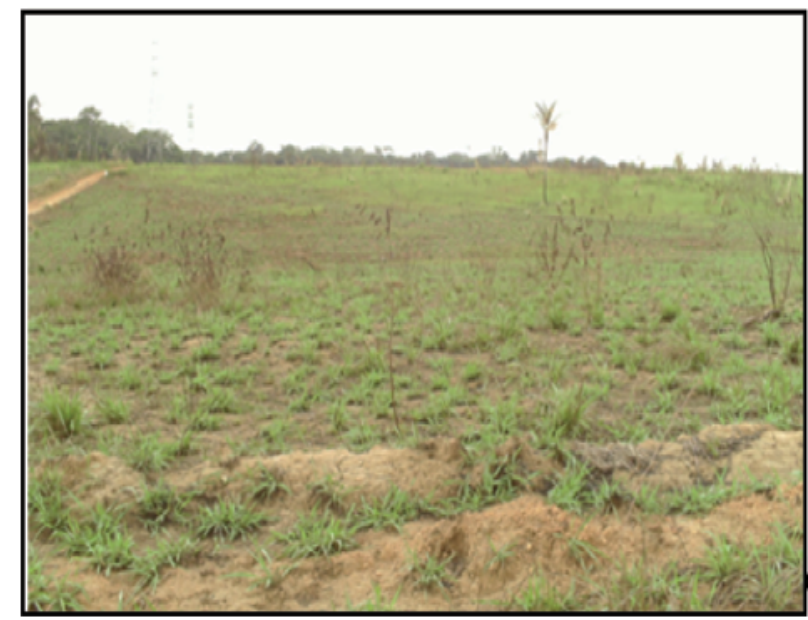

Figura 17 - Superficie suavemente plana (Fotos Santos, 2010) 


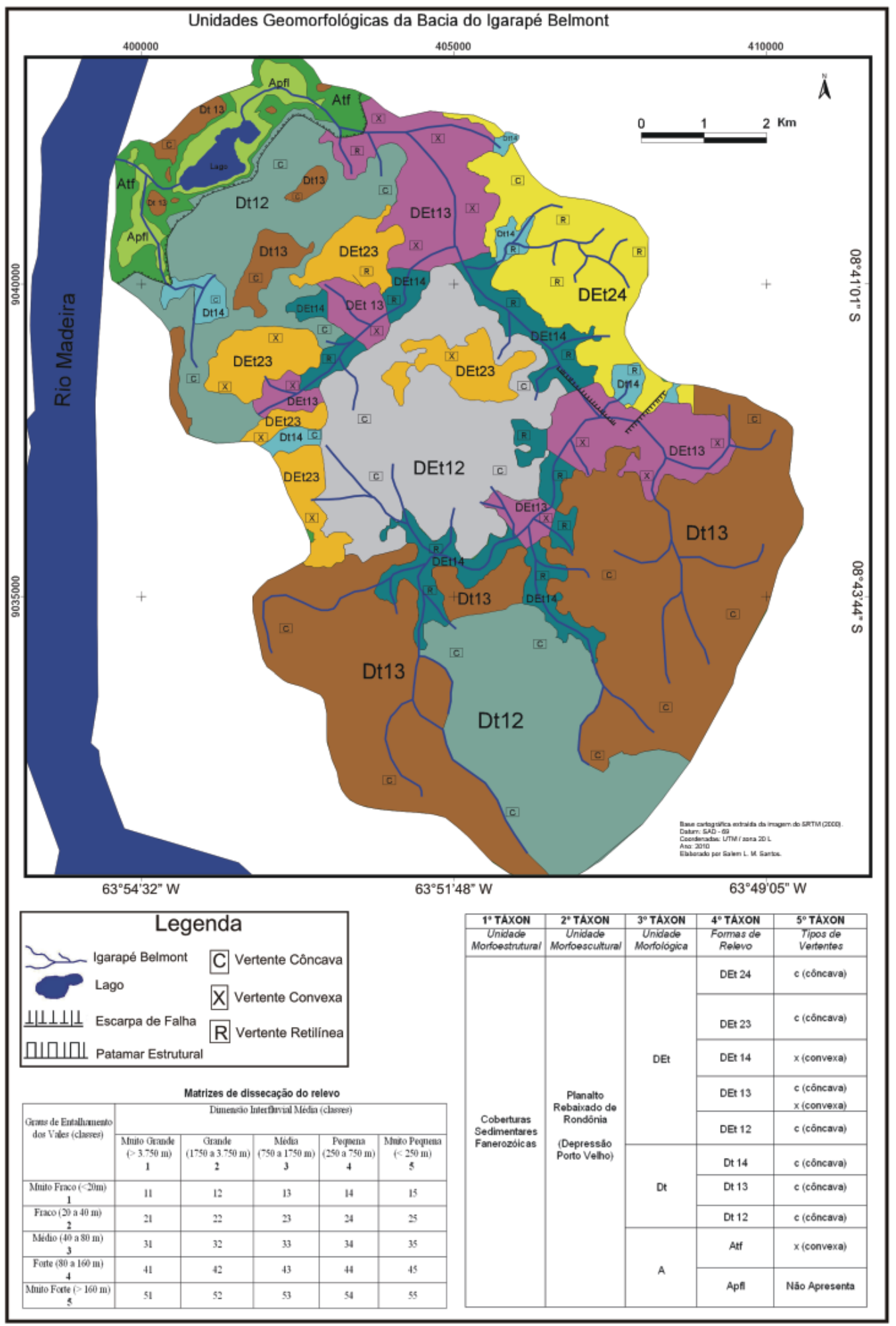

Figura 18 - Unidades Geomorfológica da Bacia do Igarapé Belmont (SANTOS, 2010). 


\section{Modelado de Dissecação}

Denudacional Estrutural Tabular com fraco entalhamento dos vales e pequena dimensão interfluvial.

Superficie dissecada apresentando fraco grau de entalhamento dos vales (de 10 a 30 metros de profundidade) e pequena dimensäo interfluvial (de 400 a 730 metros de distância), apresentando vertentes ingremes com formato côncavo, com incidências de erosões lineares e ravinamentos rasos de origem antrópica. Sua superficie eventualmente é sustentada por coberturas DetritoLateriticas.

Denudacional Estrutural Tabular com fraco entalhamento dos vales e média dimensão interfluvial.

Superficie dissecada apresentando ser colinas convexadas, de fraco grau de entalhamento dos vales (de 8 a 22 metros de profundidade), e média dimensão interfluvial (de 750 a 1.500 metros de distância), apresentando vertentes ingremes com formato côncavo, geralmente suas superficies săo sustentadas por coberturas Detrito-Lateriticas, apresentando processos erosivos lineares e ravinamentos leves de origem antrópica.

DEt 14 Denudacional Estrutural Tabular com muito fraco entalhamento dos vales e pequena dimensão interfluvial.

Superficie dissecada e deprimida da bacia do Belmont, com muito fraco grau de entalhamento dos vales (de 2 a 7 metros de profundidade) e pequena dimensão interfluvial (de 400 a 750 metros de distância), com vertentes no formato convexo escarpas nas bordas em resultados aos processos erosivos lineares e linhas de falhas, que drenam e estabilizam o curso do Igarapé para estas áreas mais deprimidas, apresentando assoreamentos dos cursos d'água de origem antrópica.

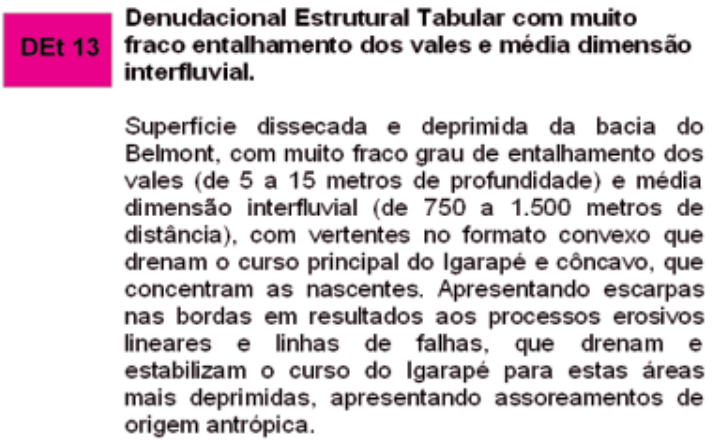
Denudacional Estrutural Tabular com muito
fraco entalhamento dos vales e grande dimensão interfluvial.

Superficie dissecada e plana, localizada entre linhas falhas, que orientam os cursos d'águas do Igarapé em um formato retangular, com muito fraco grau de entalhamento dos vales (de 3 a 15 metros de profundidade) e grande dimensăo interfluvial (de 3.000 a 3.700 metros de distância), com vertentes no formato côncavo, concentrando nascentes e apresentando processos erosivos lineares entalhamento dos vales e pequena dimensão interfluvial.

Superficie dissecada e deprimida, localizada entre relevos estruturais, com muito fraco grau de entalhamento dos vales (de 9 a 18 metros de profundidade) e pequena dimensăo interfluvial (de 300 a 630 metros de distância), com vertentes no formato côncavo, apresentando processos erosivos ineares e ravinamentos leves em decorrência da declividade do relevo.

Denudacional Tabular com muito fraco entalhamento dos vales e média dimensão interfluvial.

Superficie dissecada e plana, abrigando superficies Detrito-Lateriticas, que se encontram mais elevados do que os relevos vizinhos, com muito fraco grau de entalhamento dos vales (de 3 a 10 metros de profundidade) e média dimensăo interfluvial (de 750 a 1.300 metros de distância), com vertentes no formato côncavo concentrando nascentes, apresentando processos erosivos lineares e assoreamentos de origem antrópica.

Denudacional Tabular com muito fraco entalhamento dos vales e grande dimensão interfluvial.

Superficie dissecada e plana apresentando caracteristicas de embaciamento, com muito fraco grau de entalhamento dos vales (de 2 a 6 metros de profundidade) e grande dimensão interfluvial (de 1.800 a 2.700 metros de distância), com vertentes no formato côncavo concentrando nascentes, apresentando processos erosivos lineares $e$ assoreamentos de origem antrópica.

\section{Modelado de Agradação}

\section{Terraço Fluvial}

Superficie plana ou levemente inclinada, constituida por depósito sedimentares do periodo Terciário Quaternário, que foram modelados topograficamente pela erosão fluvial do Rio Madeira e limitados por declives no mesmo sentido dos depósitos. Apresentando retomada dos processos erosivos de forma difusa de sedimentos finos. Este relevo apresenta patamares estruturais que interrompem $\circ$ declive continuo da área, modificando o modelado da Bacia de denudacional para agradacional.

\section{Planicie Fluviolacustre}

Superficie deprimida, embaciada, constituida por depósitos do periodo do Terciário e principalmente Quaternário. Este relevo abria o Lago do Belmont e áreas de várzeas com acumulação sedimentar fluvial e lagunar.

Figura 19 - Legendas (SANTOS, 2010). 


\section{Conclusão}

Estudo realizou a classificação taxonômica do relevo conforme proposto por Brasil (1995, p.11), ao nível do $5^{\circ}$ táxon, na área da bacia do Igarapé Belmont localizada no município de Porto Velho - RO, em uma escala de detalhe de 1:25.000. Também foram identificados os tipos de processos erosivos atuantes nos modelados, sem contudo, realizar-se classificações a nível do $6^{\circ}$ táxon.

De acordo com a escala de análise e classificação metodológica encontrou-se na Bacia do Belmont 2 tipos de gênesis de relevo e 10 tipos de modelados do relevo.

No que se referem à metodologia aplicada, as dificuldades encontradas são referentes à simbologia a serem utilizadas em mapas de escalas de detalhe, pois os mapas existentes na área da Bacia estão em escalas que variam de semi-detalhe à genérica, que não apresentam classificações tipológicas das vertentes.

O uso da imagem SRTM proporcionou agilidade para a delimitação das diferentes unidades de relevo, bem como, auxiliou nas medições interfluviais.

Observando-se o mapa geomorfológico inicial, (RONDÔNIA, 2002), em escala 1:250.000, e o mapa final contido, considera-se que houve avanço qualitativo no detalhamento das feições geomorfológicas da área mapeada.

\section{Referências bibliográficas}

ARGENTO, Mauro S. F. Mapeamento Geomorfológico. Capítulo 9, IN: GUERRA, A. J T. e CUNHA, S. B. Geomorfologia Uma Atualização de Bases e Conceitos. $3^{\circ}$ Edição. Bertrand editora. Rio de Janeiro, 1998.

BRASIL, Diretoria de Serviços Geográficos - DSG. Exército Brasileiro. Carta Topográfica Porto Velho, 1:50.000 (folha SC-20 V-B-V-1). Brasília, 1972.

BRASIL, Ministério de Minas e Energia. Projeto Radambrasil - Folha SC 20. Brasília, 1982.

BRASIL, Companhia de Pesquisa em Produção Mineral CPRM. Livro Texto Explicativo da Carta Geológica Porto Velho 1:100.000. CPRM. Porto Velho, 1990.
BRASIL, Instituto Brasileiro de Geografia e Estatística - IBGE. Manual Técnico de Geomorfologia. $1^{\circ}$ edição. Rio de Janeiro, 1995.

BRASIL, Companhia de Pesquisa em Produção Mineral CPRM. Livro Texto Explicativo do Mapa Geológico de Rondônia 1:1.000.000. CPRM. Porto Velho, 2007.

FERREIRA, Ivone Luzia. Estudos Geomorfológicos em Áreas Amostrais da Bacia do Rio Araguari - MG. Uma Abordagem da Cartografia Geomorfológica. Universidade Federal de Uberlândia - MG. Dissertação de Mestrado. Uberlândia, 2005.

GUERRA, Antonio José Teixeira. MARÇAL, Mônica dos Santos. Geomorfologia Ambiental. Bertrand. $1^{\circ}$ Edição. Rio de Janeiro, 2006.

PORTO VELHO, Secretaria Municipal do Meio Ambiente SEMA. Plano de Manejo da Unidade de Conservação Olavo Pires (Parque Ecológico). Porto Velho, 2003.

RODRIGUES, Sílvio Carlos. Análise Empírico-Experimental da Fragilidade do Relevo-Solo no Cristalino do Planalto Paulistano: Sub-bacia do Reservatório Billings. Tese de Doutorado. FFLCH-USP, São Paulo. 267p. 1998.

RONDÔNIA, Secretaria de Estado do Planejamento. Plano Agroflorestal e Pecuário de Rondônia - PLANAFLORO (banco de dados geográfico). Porto Velho, 2002.

ROSS, Jurandyr Luciano Sanches. O Registro Cartográfico dos Fatos Geomorfológicos e a Questão Taxonômica do Relevo. Revista do Departamento de Geografia - USP. EDUSP Editora. $\mathrm{N}^{\circ}$ 6, Pg: 17 - 30. 1992.

SANTOS, Salem Leandro Moura dos. Avaliação das Vertentes da Bacia do Igarapé Belmont (uma contribuição para a análise ambiental). Universidade Federal de Rondônia - UNIR. Monografia de Graduação. Porto Velho, 2008.

SANTOS, Salem Leandro Moura dos. Mapeamento Geomorfológico e Geoambiental da Bacia do Igarapé Belmont - Porto Velho - Rondônia. Universidade Federal de Rondônia - UNIR. Dissertação de Mestrado. Porto Velho, 2010 .

TRICART, Jean. Príncipes et Méthodes de la Geomorphologie Masson. Editeurs. Paris. 1965. 